\title{
Prólogo y agradecimientos
}

El español es actualmente el segundo idioma con más difusión a nivel mundial y la importancia de este idioma es muy evidente en países como Estados Unidos. Tomando como ejemplo esta nación, en ella residen y trabajan hoy en día un gran número de personas en las que confluyen las dos características siguientes: por un lado, estas personas han tenido o tendrán nociones jurídicas propias del common law, pero trabajan o desean trabajar en un ámbito legal que cada vez es más globalizado y en el que el civil law también desempeña un papel relevante. Por otro lado, estas personas tienen nociones del idioma español porque lo estudiaron en la escuela o han residido en países hispanoparlantes, algún familiar cercano tiene el español como lengua materna o incluso ellos mismos han crecido oyendo el español en un registro coloquial. Sin embargo, estas nociones lingüísticas no son suficientes para que se hallen cómodos manejando un lenguaje tan técnico y especializado como es el español jurídico.

Para todo aquel que se sienta identificado con el perfil recién presentado, el libro El derecho en español le va a ser de gran utilidad, ya que permite mejorar considerablemente las capacidades jurídicas y lingüísticas de quien lo utilice. Los ejercicios que en él se contienen han sido cuidadosamente diseñados desde una perspectiva pedagógica, con el objeto de ayudar a potenciar las habilidades lectoras y auditivas de los usuarios, así como su expresión escrita y oral.

Para conseguir dichos objetivos, el libro se presenta estructurado en diez capítulos, ofreciendo todos ellos - salvo el último- un mismo formato conformado por cinco ejercicios. Cada capítulo salvo el primero y el último- está dedicado a una específica rama 
del derecho y en él se trabaja tanto el español legal de Latinoamérica como el de España.

Se trata de una obra monolingüe, dirigida a quienes tengan un nivel medio de español. Aunque es preferible poseer también unos conocimientos jurídicos básicos, se estima que este libro puede ser también el aliciente perfecto para hacer que un lego en el derecho se adentre en el estudio de esta materia. El libro puede ser utilizado como manual para clases impartidas en colegios, universidades, escuelas de idiomas y academias especializadas en preparación de oposiciones. Asimismo, el libro puede ser utilizado como herramienta de autoaprendizaje por todo aquel que desee mejorar su español jurídico y de esta forma poder cumplir exitosamente con sus aspiraciones personales y laborales (abogados, paralegals, traductores, intérpretes, funcionarios públicos, profesores, entrepreneurs, trabajadores en organizaciones no gubernamentales u organizaciones internacionales vinculadas con Latinoamérica o España, etc.). Resulta indiscutible que los intercambios comerciales con Latinoamérica y España generan un gran volumen de negocio, de la misma forma que en muchos países los inmigrantes hispanoparlantes requieren y seguirán requiriendo gran cantidad y variedad de servicios jurídicos. Por ello, potenciar de forma combinada las capacidades jurídicas y lingüísticas en español es sinónimo de un mejor posicionamiento en un mercado laboral que cada vez con más frecuencia demanda el perfil profesional que aspiran alcanzar los lectores de este libro.

Este libro trae su origen en las clases impartidas por la autora en Fordham Law School (Nueva York) durante los años 2010 y 2011. El perfil de los-fantásticos-estudiantes que se matricularon en mi disciplina me hizo comprender que un libro como éste podía ser de gran utilidad para muchas personas. Por ello, le estoy muy agradecida a Toni M. Fine, Assistant Dean for International and Non-J.D. Programs, por contagiarme su irrefrenable ilusión por el proyecto. Asimismo, gracias a Sheila Foster, Associate Dean for Academic Affairs, por atenderme con tremenda eficacia y apoyar mis iniciativas. Ce- 
rrando la terna femenina, gracias también a Cynthia Juco, Esq., Senior Counselor, por confiar en mí y tratarme siempre con elegancia. Por último, mi más sincero agradecimiento a Profesor Alejandro Garro, porque sin su apoyo, en éste y en muchos otros proyectos, nunca me habría atrevido a pensar que podía ser capaz de volar.

Katia Fach Gómez 
THIS PAGE INTENTIONALLY LEFT BLANK

Esta página no contiene texto intencionalmente. 


\section{Introducción}

\section{Cómo usar este libro}

Como se ha indicado, los capítulos 1 a 9 de este libro están conformados por cinco tipos de ejercicios. Estos ejercicios le permiten al alumno un aprendizaje progresivo, ya que conforme se va avanzando en el análisis del capítulo el usuario se va capacitando para afrontar actividades de creciente complejidad jurídica y lingüística. El Ejercicio 1 es el punto de partida de cada uno de los capítulos. Los abundantes términos jurídicos que se recogen en esta actividad inicial constituyen palabras claves del ámbito jurídico a que se dedica cada capítulo. Las actividades que caben realizar con dicho vocabulario son muy variadas y pueden llevarse a cabo tanto desde el contexto escrito como desde el oral. Así, se puede pedir al alumno que explique el significado de los términos que conozca y/o busque e interiorice el significado de los términos que desconozca; se le puede requerir que incorpore las palabras del listado a un contexto, escribiendo frases con ellas y/o elabore redacciones que contengan un determinado número de estas palabras; la actividad también puede centrarse en que el estudiante descubra algunas palabras que sólo se usan en el contexto latinoamericano u otras que son típicas de España o que esa lista inicial se aumente aportando sinóminos y/o antónimos, sustantivando un verbo o "verbalizando" un sustantivo. El nivel de dificultad del Ejercicio 1 depende en gran medida del profesor o del propio estudiante que use este libro como mecanismo de autoaprendizaje. Ellos son los encargados de precisar una multiplicidad de factores: si se revisan todos los términos del listado o sólo parte de ellos; cuántas palabras del Ejercicio 1 se requiere que se incorporen a cada redacción o diálogo; qué tiempo se otorga a la realización del ejercicio, si éste se realiza en clase o como trabajo previo 
a la clase presencial, etc. Los conocimientos previos del estudiante son obviamente otra variable que aporta más relatividad a esta cuestión. No obstante, teniendo en cuenta todos estos parámetros, se sugiere que el Ejercicio 1 no "desborde" al alumno pero que al mismo tiempo le de un sustrato suficiente para poder afrontar con éxito los ejercicios venideros.

Una vez que se conoce el vocabulario básico en la materia y se han realizado unos primeros esfuerzos contextualizadores, es necesario que el usuario avance en el conocimiento jurídico y lingüístico de cada área del derecho. Para ello, los Ejercicios 2 y 3 ofrecen un mayor contexto operacional. De forma consciente, en estos ejercicios de rellenado de huecos y conformación de frases, se mezcla vocabulario procedente del Ejercicio 1 con vocabulario nuevo que se desea que el alumno conozca. Si estos ejercicios pueden calificarse de nivel de dificultad medio, los Ejercicios 4 y 5 por su parte aportan un nivel de dificultad medio-alto. En ellos, la lectura de textos jurídicos en español y la resolución posterior de cuestionarios tipo test de opción múltiple o verdadero/falso requieren del alumno un mayor conocimiento de la materia y al mismo tiempo son el mecanismo perfecto para que los estudiantes realicen sus primeras incursiones en el derecho comparado. Como se ha indicado en el prólogo, gran parte de los usuarios de este libro proceden de un país con una tradición jurídica distinta a la imperante en Latinoamérica y España. Por ello, el aprendizaje contextualizado de términos y expresiones legales les va a conducir de forma natural a la comprensión de las distinciones imperantes entre sistemas jurídicos. Si el libro se utiliza en un aula, el profesor puede, al hilo de la resolución de los ejercicios, ilustrar a la clase con explicaciones de carácter más teórico sobre la materia objeto de estudio. Si se acude al libro como herramienta de autoaprendizaje, el usuario puede acudir a una pluralidad de recursos (manuales, monografías, artículos, bases de datos, etc.) para profundizar en el análisis de las cuestiones jurídicas que se le vayan planteando al ir resolviendo los ejercicios de El derecho en español.

Este libro también ofrece el capítulo 10, en el que se propone un 
análisis jurídico de varias películas de cine. Los ejercicios que en él se sugieren pueden servir tanto para fomentar los debates grupales, el role playing y las presentaciones orales individuales en clase como también para ofrecer abundantes temas jurídicos respecto de los cuales los alumnos pueden elaborar redacciones más extensas o trabajos escritos de fin de curso. Tampoco puede obviarse el positivo efecto que va a tener sobre los estudiantes la escucha de distintos acentos y giros lingüísticos procedentes de diversos países. Por último, el libro concluye con un apéndice en el que se recogen las respuestas correctas a todos los ejercicios planteados. Ello es de gran utilidad, tanto si el libro se utiliza como manual de clase como si se emplea en la modalidad de autoaprendizaje. 
THIS PAGE INTENTIONALLY LEFT BLANK

Esta página no contiene texto intencionalmente. 
El derecho en español 
THIS PAGE INTENTIONALLY LEFT BLANK

Esta página no contiene texto intencionalmente. 